\title{
NARRATIVIDAD E INTERPRETACIÓN: NEXOS ENTRE LA INVESTIGACIÓN NARRATIVA Y LA HERMENÉUTICA
}

- LUIS GABRIEL PORTA

Universidad Nacional de Mar del Plata - CONICET

GRACIELA NELIDA FLORES

Universidad Nacional de Mar del Plata

RESUMEN A partir de nuestra situacionalidad como investigadores en educación que asumimos el enfoque narrativo, nos abocamos a explicitar en el presente artículo los nexos fundamentales entre hermenéutica y narratividad, teniendo en cuenta que la hermenéutica filosófica constituye uno de los principales fundamentos de la investigación narrativa porque este enfoque interpreta vivencias lingüistizadas y pretende alcanzar una comprensión de las experiencias de los sujetos. Recuperamos los antecedentes filosóficos más cercanos que han influido en el giro hermenéutico, mostrándolos en vinculación con tres ejes centrales de la investigación narrativa en educación: comprensión e interpretación, subjetividad e intersubjetividad, vivencia y experiencia. Estos ejes de sentido portan su historicidad, su explicitación contribuye a identificar la solidez del enfoque narrativo como vía privilegiada para la construcción de conocimiento mediante las narrativas de los protagonistas.

Palabras clave: Investigación narrativa. Giro hermenéutico. Interpretación. Comprensión.

\section{ABSTRACT}

\section{NARRATIVITY AND INTERPRETATION: LINKS BETWEEN}

\section{NARRATIVE REASERCH AND HERMENEUTICS}

This work aims at making explicit the fundamental links between hermeneutics and narrative. From an educational researcher site we assume a narrative framework understanding philosophical hermeneutics as one of the basis for narrative research. This approach illuminates life experiences expressed through language and expects to reach an understanding of the subjects' experiences. We recover recent philosophical antecedents which have influenced the hermeneutical turn in relation with three key concepts of narrative research 
in education: understanding and interpretation; subjectivity and inter-subjectivity, life experience and experience. These significant notions carry their own historicity; making them explicit helps identify the strength of the narrative approach as an extraordinary way for the construction of knowledge through protagonists' narratives.

Keywords: Narrative Research. Hermeneutical Turn. Interpretation. Understanding.

\section{RESUMO NARRATIVIDADE E INTERPRETAÇÃO: LIGAÇÕES ENTRE A PESQUISA NARRATIVA E A HERMENÊUTICA}

Como pesquisadores educacionais que assumem a abordagem narrativa, vamos nos concentrar para explicar, neste artigo, as ligações fundamentais entre hermenêutica e narrativa, considerando que a hermenêutica filosófica é uma das principais bases da pesquisa narrativa, pois esta abordagem interpreta experiências linguistizadas e procura alcançar uma compreensão das experiências dos sujeitos. Temos a intenção de recuperar o fundo filosófico mais próximo que influenciou o giro hermenêutico, mostrando os três temas centrais da pesquisa narrativa em educação: compreensão e interpretação, subjetividade e intersubjetividade, vivência e experiência. Estes eixos de sentido têm a sua historicidade, cuja clareza ajuda a identificar a força da abordagem narrativa como meio privilegiado para a construção de conhecimento através da narrativa dos protagonistas.

Palavras-chave: Compreensão. Giro hermenêutico. Interpretação. Pesquisa narrativa.

\section{Introducción}

La investigación narrativa en educación es interdisciplinar porque en este enfoque confluyen antropología social, etnografia, sociología, teoría lingüística y literaria y filosofía hermenéutica; un rasgo compartido es que "todas ellas coinciden en cuanto se interesan en los modos como los humanos dan significado a su mundo mediante el lenguaje" (BOLÍVAR, DOMINGO y FERNÁNDEZ, 2001, p. 53)1.

1 Los autores ofrecen diversos aportes en torno a la perspectiva narrativa en la investigación educativa. Son pioneros de la investigación biográfico-narrativa en educación en el ámbito iberoamericano, su trayectoria de trabajo se inscribe en el grupo de investiga-
Es posible afirmar que todas las corrientes de la filosofía contemporánea, como dice Apel (1985) convergen desde hace décadas en "la problemática del sentido, la comprensión y el lenguaje" (p. 265) esto es notorio tanto en la filosofia analítica del lenguaje como en la filosofía hermenéutica. Aunque ambas inciden en la perspectiva investigativa narrativa, nos ocuparemos de la segunda principalmente porque permite profundizar el problema de la com-

ción de la Facultad de Ciencias de la Educación de la Universidad de Granada denominado "Formación del Profesorado Centrada en la Escuela" (FORCE). 
prensión, que es inherente a los propósitos investigativos de quienes como integrantes del GIEEC (Grupo de Investigaciones en Educación y Estudios (ulturales) ${ }^{2}$ estamos involucrados en un enfoque narrativo interpretativo.

Nos abocamos a una perspectiva filosófica porque dentro de las nuevas configuraciones del pensamiento social el "giro hermenéutico" ha provocado entender los fenómenos sociales (por tanto, a la educación) como "textos". De tal modo la "hermenéutica narrativa" permite comprender la complejidad de las narraciones de los individuos y destacar el valor y el significado de las acciones humanas, que vienen dados por la "autointerpretación hermenéutica" de los propios agentes, pero el investigador como intérprete dialoga con sus entrevistados, dialoga luego con los textos surgidos de las entrevistas o registros, sin excluir el reconocimiento de sí mismo como sujeto portador de significados (BOLÍVAR, DOMINGO y FERNÁNDEZ, 2001, p. 59), así se produce algún grado de coautoría en la narración y una interpretación de las narrativas que aportará comprensión a las problemáticas investigadas.

Si bien las narrativas de los sujetos conllevan una instancia de autointerpretación, el enfoque narrativo involucra la intersubjetividad y la conversación (en sentido gadameriano) así se superan tanto la razón monológica como la racionalidad instrumental, porque el enfoque narrativo:

[...] es un campo de indagación sensible, donde el análisis es ante todo interpretativo, herme-

2 El GIEEC, radicado en la Facultad de Humanidades de la Universidad Nacional de Mar del Plata, dirigido por el Dr. Luis Porta y conformado por docentes de diversas disciplinas, desde el año 2003 viene indagando cuestiones relacionadas con la didáctica en el Nivel Superior. Venimos estudiando la enseñanza de un grupo de profesores que fueran elegidos por estudiantes avanzados de las carreras de profesorado como ejemplos de buena enseñanza. Por tratarse de docentes que dejan huellas en la memoria y en la vida de sus alumnos, nos referimos a ellos en nuestras publicaciones como "profesores memorables" (PORTA, SARASA y ÁLVAREZ, 2011). néutico, donde lo que importa es la sutil relación -no equiparable- entre vida, experiencia y palabra, y donde lo emocional, en el profundo sentido de la relación dialógica, es un factor determinante [...] (ARFUCH en SARASA, 2010, p. 190).

Es posible que al aludir a un "análisis" hermenéutico se identifique hermenéutica con interpretación, esto conlleva el riesgo de reducir la profundidad filosófica y la historicidad de la hermenéutica, que ha sufrido grandes transformaciones que merecen ser consideradas para entender el complejo entramado que fundamenta la investigación narrativa.

La hermenéutica cobra un sentido renovado mediante el "giro hermenéutico" de la filosofia, que constituye uno de los principales fundamentos de la investigación narrativa, y esto es así, porque desde la perspectiva de los investigadores interpretativos el análisis sistemático del "significado subjetivo" es esencial en la investigación sobre la enseñanza (ERICKSON, 1997, p. 214) y porque el enfoque narrativo toma a los relatos de los sujetos como género discursivo específico.

El enfoque narrativo produce una recuperación de las experiencias de los protagonistas de la educación según su propia perspectiva. La singularidad y subjetividad de los relatos no implican subjetivismo ni relativismo gnoseológico, sino una superación de la dicotomía ocurrida en el campo narrativo que consiste en oponer los relatos con pretensión de verdad y los relatos de ficción. Según Ricoeur (1997) esa dicotomía generó una fragmentación en el acto de narrar, para el filósofo "existe una unidad funcional entre los múltiples modos y géneros narrativos" (p. 480), contra la división tajante entre relatos de ficción y relatos con pretensión de verdad opone su hipótesis de que existe reciprocidad entre narratividad y temporalidad, que todo lo que se desarrolla temporalmente puede narrarse y a su vez, un proceso temporal puede reconocerse como tal en 
la medida que pueda narrarse de algún modo, se trata de reconocer que el carácter temporal es el carácter común de la experiencia humana, señalado, articulado y aclarado por el acto de narrar en todas sus formas. Comprender que esa división tajante entre ficción y verdad es superada por el reconocimiento de la unidad narrativa de la vida conlleva asumir que la construcción narrativa no puede clasificarse en esos parámetros. Las narrativas de los sujetos que participan en la realidad educativa investigada permiten comprender la realidad en la que viven; sus tramas y sus argumentos dan cuenta de una construcción con pretensión de veracidad y de sentido.

\section{La hermenéutica en la investigación narrativa en educación}

La perspectiva narrativa en educación se vincula al giro producido en los setenta en ciencias sociales desde la instancia tradicional positivista a una perspectiva interpretativa, "dentro del giro hermenéutico en filosofia y ciencias sociales, la narratividad ha llegado a adquirir el status de forma primaria por la que le es dado sentido a la experiencia humana" (DOMINGO y FERNÁNDEZ, 2001, p. 89).

Este enfoque investigativo conlleva el problema hermenéutico, éste se ha suscitado a partir de los límites de la exégesis, porque toda lectura de un texto siempre está ligada a una comunidad, a una tradición o a una corriente de pensamiento vivo. Como dice Ricoeur (1975a) "hay interpretación allí donde existe sentido múltiple, y es en la interpretación que la pluralidad de sentidos se hace manifiesta (p. 17).

La multiplicidad de sentidos también involucra la problematicidad de la "dualidad de la hermenéutica", porque en ella coexisten el surgimiento de símbolos nuevos y el resurgi- miento de símbolos arcaicos, esta dualidad de los símbolos significa que son temporalmente regresivos y prospectivos (RICOEUR, 1975b, p. 25). Ricoeur (1997) propone considerar otro problema que consiste en identificar la característica más importante del acto de hacer-relato, que es que no significa una estructura estática sino una operación, que es una elaboración de la trama. La trama es la mediadora entre el acontecimiento y la historia, el acontecimiento desde esta perspectiva no es una incidencia sino un componente narrativo, la trama los ensambla y los compone. "De este carácter inteligible de la trama se deduce que la capacidad para seguir la historia constituye una forma muy elaborada de comprensión" (RICOEUR, 1997, p. 481). Y en esta comprensión se da el círculo hermenéutico entre el intérprete y el texto porque el intérprete está dentro de la "vida", no es un observador teórico sino que pertenece a la totalidad de la vida en la que participa (GADAMER, 1998, p. 139).

En el marco de la investigación narrativa en educación la narrativa se entiende como un tipo especial de discurso donde una experiencia humana es expresada en un relato, esto se enmarca en una tesis fuerte: que los humanos construimos nuestra existencia dentro de una "estructura" narrativa. Esta tesis se vincula con la noción de "identidad narrativa" de filósofos como Ricoeur (1996) o Maclntyre (1984).

MacIntyre (1984) piensa que las acciones tienen básicamente carácter histórico, las historias se viven antes de expresarlas en palabras, lo que ocurre es que vivimos narrativamente nuestras vidas y entendemos nuestras vidas en términos narrativos, entonces "la forma narrativa es la apropiada para entender las acciones de los demás" (p. 261). Puesto que los seres humanos leen e interpretan su propia experiencia y la de los otros en forma de relato se hace referencia a un "yo" dialógico, en sus narrativas el sujeto expresa su modo de 
estar comprometido con los otros y asume la responsabilidad de responder de sus pensamientos, sentimientos y acciones.

El relato como forma específica del discurso se organiza en torno a una trama argumental, secuencia temporal, personajes y situaciones y esto se realiza dentro de pautas culturales establecidas. Los investigadores que realizamos investigación narrativa en educación consideramos que las instituciones en las que viven las sociedades humanas son comprendidas, transmitidas y reformadas, o sea, co-determinadas, por la autocomprensión interna de los sujetos que conforman la sociedad, y esas realidades sociales se expresan en conciencia lingüísticamente articulada.

En sentido más preciso, lo que se comparte básicamente al asumir un enfoque narrativo, es cierto posicionamiento ante la "condición humana" (ARENDT, 2007) alejado de visiones biologicistas o metafísicas. El enfoque se aleja del esencialismo y se vincula con posiciones como las de Taylor (1996) quien sostiene que la característica antropológica distintiva del hombre es que se autointerpreta, y que no hay estructura de significado para el ser humano independiente de su interpretación. También se vincula con posiciones como la de Mélich (2006) quien piensa que el ser humano es un homo narrans porque está enredado en historias, porque vive en la tensión entre lo que hace y lo que le sucede, porque el sentido de la vida no es algo definitivamente hallado, entonces:

[...] solamente a través de la narración, del relato siempre dinámico y cambiante de nuestra existencia, cada ser humano puede inventar el sentido de su vida. Y es a través de las narraciones que nos cuentan y que nos contamos como configuramos nuestra identidad, una identidad siempre en devenir, siempre provisional [...] (MÉLICH, 2006, p. 43).

Se trata de concepciones que priorizan la temporalidad, el lenguaje y la construcción de sentidos, en contraste con el yo fundante cartesiano. La narratividad es rasgo vital cuando se piensa, como MacIntyre (1984) que el ser humano "es esencialmente un animal que cuenta historias" tanto en sus acciones, en sus ficciones, como en sus prácticas (p. 266). La importancia del método hermenéutico en este contexto es que "[...] coloca la experiencia histórica de los protagonistas por encima de toda deducción abstracta, asi como de toda pretensión transcendental [...]" (MALIANDI, 2004, p. 90).

Luego de este breve marco que permite comprender la importancia de la narratividad como dimensión constitutiva de la condición humana, nos abocamos a indagar los antecedentes de algunos conceptos centrales de la investigación narrativa que se vinculan con el aludido giro hermenéutico, para lo cual recurrimos a algunos filósofos, principalmente al máximo representante de la hermenéutica contemporánea, Gadamer $(1998,2003)$ porque contribuye a nuestro propósito de mostrar algunas transformaciones en sentido filosófico-histórico en los conceptos de sujeto, intersubjetividad, comprensión y vivencia, porque se trata de antecedentes filosóficos relevantes cuando los investigadores buscan fundamentar la perspectiva investigativa narrativa. En este sentido Gadamer nos ofrece aportes porque como él mismo expresa cuando habla de su labor filosófica: "El caso es que sigo desde hace tiempo el principio metodológico de no emprender nada sin rendir cuentas de la historia que se esconde detrás de los conceptos" (GADAMER, 1998, p.12).

\section{Historicidad de la hermenéutica. Nexos fundamentales entre hermenéutica y narratividad}

\section{a. La comprensión hermenéutica}

Como hemos señalado en Flores, Porta y Martín Sanchez (2014), el método hermenéutico fi- 
losófico cobró especial importancia a partir de la obra de Dilthey y su distinción entre ciencias "explicativas" y ciencias "comprensivas". Al referirse a la historicidad de la hermenéutica, Apel (1985) aclara que el término "hermenéutica" fue un neologismo derivado del griego que en el siglo XVII reemplazó la expresión latina y humanista de la ars interpretandi y fue una técnica dedicada a "la praxis de mediación lingüístico-literaria de la tradición puesta particularmente al servicio de las religiones escritas" (p. 269) pero mucho después Schleiermacher (1768-1834), marcó un punto de inflexión en esta historia, al elevar la "comprensión" a tema de la teoría filosófica del conocimiento independientemente de los vínculos dogmáticos de la interpretación bíblica. Luego Dilthey (1833-1911), estableció que la "comprensión" es el concepto metodológico fundamental de las "ciencias del espíritu" y planteó que el sujeto del comprender debe concebirse como "vida" que en la "vivencia" y en la expresión de la vivencia se comprende a sí misma, entonces, para comprender la vida ajena es necesario comprenderse a sí mismo como vida, esta concepción, según la cual la vida humana es comprensible desde dentro, trasciende la separación cartesiana sujeto-objeto. Más tarde Heidegger (1889-1976) realizó una "radicalización filosófica de la hermenéutica", concibió el lenguaje como autointerpretación del ser en la comprensión humana de uno mismo y del mundo (APEL, 1985, pp. 270-271). Dilthey concebía la hermenéutica como un arte de comprender conexiones de sentido, en cambio Heidegger propuso una hermenéutica que podríamos considerar ontológica. Con Heidegger (1998) confluyen fenomenología y hermenéutica, al ocuparse de la problemática del "comprender" humano como una estructura fundamental del Dasein.

Una hermenéutica "tradicional" encuentra su lugar científico teórico en la jurisprudencia, la teología y la filología. Schleiermacher, Dilthey y Heidegger no pertenecen a esta tradición hermenéutica, y son ellos quienes inciden en la hermenéutica gadameriana. Como dice Maliandi (2004), para Gadamer (1900-2002) la hermenéutica cumple una "función" filosófica, interesada en investigar la historicidad del comprender; asi es que contra la deshistorización, defiende la "verdad" del recordar, el comprender es concebido por el mencionado filósofo como una “interpretación esencialmente ligada al intérprete y a la particular situación histórica de éste" (p. 90).

Para Dilthey el único lugar en que los problemas hermenéuticos tienen cabida es la psicología, es la recepción posterior de su obra y el influjo que ejerció su escuela, lo que afianzó la hermenéutica, en la filosofía vital de Dilthey, se anuncia el giro hermenéutico. Husserl (1859-1938) reprochaba a Dilthey que si se parte de la vida histórica se llega al relativismo y al escepticismo, Dilthey insistía en que hay que aceptar encontrarse en el mundo de la vida, así la filosofía de la vida va en contra de la subjetividad trascendental de Husserl y en contra de su interpretación trascendental de la fenomenología, se trata de pensar "desde" la vida (mismo punto de partida de Heidegger). Mostrar esta diferencia permite entender la posición de Gadamer (1900-2002):

Hermenéutica se refiere sobre todo a que hay algo ahí que se dirige a mí y me cuestiona a través de una pregunta. Esta es la razón de que el lenguaje sólo puede ser en la conversación lo que puede ser, pues es en el juego de pregunta y respuesta donde ofrece una perspectiva que no se encuentra ni en la mía ni en la del otro (GADAMER, 1998, p. 146).

En la hermenéutica no hay nunca un principio primero ni una eliminación del sujeto en favor de la objetividad de la ciencia, está incluido él mismo como eslabón participativo con sentido “[...] el intérprete que intenta com- 
prender la construcción de sentido deja de ser el simple realizador de una reconstrucción [...]" (GADAMER, 1998, p. 151).

Es dificil comprender estas ideas sin tener en cuenta que el giro lingüístico también influye en el nuevo modo de entender el lenguaje, cabe recordar que, como dice Maliandi (1991) fueron protagonistas del giro lingüístico de la filosofía contemporánea, por un lado, filósofos como Peirce o Wittgenstein, pero, por otro, también como Heidegger o Gadamer. Cuando Wittgenstein o Austin pasaron al lenguaje hablado integrándolo en el contexto de actuación, liberaron al lenguaje de la presión de la lógica, pasaron del ideal lógico del lenguaje al lenguaje de la comunicación viva (Flores, Porta y Martín Sanchez, 2014). Como dice Gadamer (1998) los seres humanos construyen su mundo común con los demás, por medio del intercambio permanente que se produce en la conversación (p. 152).

En tiempos recientes Vattimo (1991) se interesa por la creciente popularidad de la hermenéutica en la cultura, ocurrida en la década de los ochenta del siglo pasado, piensa que esa difusión la ha convertido en una koi$n e^{3}$ del mundo occidental, aunque no a modo hegemónico, pero sí como pensamiento que interesa a filósofos de diferentes continentes. Según el filósofo italiano la "formulación clásica" de interpretación en la hermenéutica de Gadamer, que conlleva una conversión, una transformación de la hermenéutica, es la siguiente:

La interpretación no es ninguna descripción por parte de un observador neutral, sino un evento dialógico en el cual los interlocutores se ponen en juego por igual y del cual salen modificados, se comprenden en la medida que son comprendidos en un horizonte tercero, del cual

3 Con el término koiné Vattimo quiere significar que la hermenéutica conforma una especie de lenguaje común entre los filósofos, que fuera precedida por una koiné estructuralista, así como hubo una koiné existencialista, entre otras. no disponen sino en el cual, y por el cual, son dispuestos (VATTIMO, 1991, pp. 61-62).

Entonces el enfoque hermenéutico pone el acento en la pertenencia de observador y observado a un horizonte común, y en la verdad como evento que en el diálogo entre interlocutores pone en obra y modifica a la vez, tal horizonte.

Ahora bien, Ricoeur (1913-2005) nos permite pensar que las influencias de la hermenéutica en la investigación narrativa deben considerarse sin olvidar que hay un "arraigo" fenomenológico de la hermenéutica (RICOEUR, 1997). La filosofia reflexiva asume como importantes los problemas en torno a la posibilidad de comprensión de uno mismo como sujeto, la reflexión es el acto de retorno del sujeto a sí mismo, la fenomenología señala la primacía de la conciencia de algo, sobre la conciencia de sí (el ego cogito cogitatum husserliano) en definitiva, la intencionalidad de la conciencia. Desde la perspectiva ricoeuriana la hermenéutica resurge en tiempos de Schleiermacher de la fusión entre exégesis bíblica, filología clásica y jurisprudencia, que pudo ocurrir por el giro copernicano que significó darle primacía a la pregunta sobre qué es comprender sobre la pregunta por el sentido de algún texto.

Para Ricoeur (1997) la investigación sobre el verstehen desemboca un siglo más tarde en la investigación sobre el sentido intencional de los actos noéticos (correlación noética noemática husserliana), que es el problema fenomenológico por excelencia. La fenomenología planteaba el problema del sentido en el ámbito cognitivo y perceptivo, la hermenéutica plantea desde Dilthey el problema del sentido en el plano de las ciencias humanas y la historia, "sin embargo, en ambos casos, se trataba del mismo problema fundamental: el de la relación entre el sentido y el sí mismo, entre la inteligibilidad del primero y la reflexividad del segundo" (RICOEUR, 1997, p. 490). 
Según el filósofo francés el arraigo fenomenológico de la hermenéutica no se limita a la afinidad entre la comprensión de los textos y la relación intencional de una conciencia con un sentido que tiene delante; piensa que el tema de la Lewenswelt que es enfocado por la fenomenología, es asumido por la hermenéutica postheideggeriana como condición previa, primeramente estamos en el mundo con una pertenencia participativa, el verstehen tiene significado ontológico, la interpretación es la explicitación de este comprender ontológico, la relación sujeto-objeto se subordina a un vínculo ontológico más primitivo que cualquier condición cognoscitiva. Es una inversión heredera de la fenomenología husserliana cuya consecuencia es que "no hay comprensión de sí que no esté mediatizada por signos, símbolos y textos, la comprensión de sí coincide, en última instancia, con la interpretación aplicada a estos términos mediadores" (RICOEUR, 1997, p. 491).

Se trata de una emancipación del idealismo de la fenomenología husserliana, centrada en la mediación a través de signos, que afirma la condición originariamente lingüística de toda experiencia humana, a través de símbolos, que pueden ser tanto universales, propios de una cultura, o creados por un pensador particular, o por una obra singular, pero la hermenéutica no puede definirse simplemente como la interpretación de símbolos, la otra mediación se da a través de textos, que permite una definición de la hermenéutica como interpretación textual. Aquí, lo escrito se aleja de los límites del diálogo y se convierte en la condición del devenir texto del discurso "corresponde a la hermenéutica explorar las implicaciones que tiene este devenir-texto para la tarea interpretativa" (RICOEUR, 1997, p. 492). Esta mediación termina con la idea de la transparencia del sujeto con respecto a sí mismo, a su vez, el rodeo entre signos y símbolos se amplía en la mediación de los textos que se alejan de la condición intersubjetiva del diálogo. El filósofo cree que al liberarse de la primacía de la subjetividad, la primera tarea de la hermenéutica es reconstruir la doble labor del texto, que involucra la dinámica interna que preside la estructuración de la obra y la capacidad de la obra para dar lugar a un mundo, al proyectarse fuera de sí misma (dinámica interna y proyección externa). A la tarea corresponden los análisis orientados a articular comprensión y explicación en el plano del sentido de la obra, Ricoeur (1997) rechaza el irracionalismo de la comprensión inmediata, que en los textos sería como una extensión de la intropatía (o endopatía, o empatía husserliana) algo así como una congenialidad entre las dos subjetividades implicadas por la obra, autor y lector, y rechaza el racionalismo de la explicación que contiene la ilusión de una objetividad textual cerrada en sí misma e independiente de la subjetividad, tanto del lector como del autor.

A estas dos actitudes unilaterales opone la dialéctica de la comprensión y de la explicación, contra una reducción de la comprensión a la intropatía y a la vez contra una reducción de la explicación a una combinatoria abstracta. Señalada su posición, que aquí no profundizaremos, es pertinente a los fines de nuestro trabajo su idea de que en las tramas narrativas el discurso "quiere llevar al lenguaje una experiencia, un modo de vivir y de estar-en- el -mundo que le precede y pide ser dicho" o sea, defiende "la precedencia de un ser que pide ser dicho respecto a nuestro decir" (RICOEUR, 1997, p. 494).

\section{b. De la subjetividad a la intersubjetividad}

En la investigación narrativa se otorga una nueva jerarquía al ámbito de la subjetividad a modo de democratización de los saberes por- 
que "estas investigaciones privilegian la voz de los sujetos en su pluralidad, los tonos divergentes y la otredad" (ARFUCH, 2005, p. 23).

La narrativa puede entenderse como un modo básico de pensar, organizar el conocimiento y la realidad, puesto que las culturas se han configurado y expresado mediante narrativas, que a la vez han dado identidad a sus miembros; en la concepción constructivista bruneriana de la cultura, el significado de los conceptos sociales reside en la negociación interpersonal, se trata de llegar a compartir significados. Es decir, la cultura se recrea constantemente al ser interpretada y renegociada por sus integrantes, de tal modo la cultura es "un foro para negociar y renegociar los significados" (BRUNER, 1988, p. 128). En el marco de una psicología cultural se comprende esta concepción al considerar que "somos la especie intersubjetiva por excelencia" lo que significa que tenemos un "talento para la intersubjetividad", una habilidad para entender a los otros a través de diversos medios, como el lenguaje (BRUNER, 2012, p. 41).

Desde una perspectiva filosófica no basta ese "talento" para la "negociación" intersubjetiva, porque en la interpretación hay interpelación, como dice Gadamer (1998) "Una interpretación es siempre un asunto delicado. Ello se da ya por el solo hecho de que por su carácter (y por la palabra misma) es siempre interpelación (Zwischenrede)" (p. 114). De estas consideraciones surge la necesidad de rastrear los antecedentes filosóficos de la actual relevancia de la subjetividad, que como intentaremos mostrar, es inescindible de la intersubjetividad, puesto que pensar que las narraciones y las interpretaciones son un fenómeno puramente individual impediría cualquier intento de comprender, así como de validar la investigación narrativa e interpretativa, con más razón si tenemos en cuenta que, como dicen Bolivar, Domingo y Fernández (2001): “El enfoque narrativo da prioridad a un yo dialógico (naturaleza relacional y comunitaria de la persona), donde la subjetividad es una construcción social, interactiva y socialmente conformada en el discurso" (p. 22).

El concepto de intersubjetividad se ha generalizado a partir de la fenomenología de Husserl, su fenomenología del mundo de la vida dio lugar a nuevos planteamientos que se iniciaron a finales de la década de 1940 cuando Schütz vio en el concepto "mundo de la vida" un alejamiento del principio de subjetividad trascendental y lo usó para fundamentar las ciencias sociales, luego la filosofia social americana lo adoptó en diversos sentidos (GADAMER, 1998). La influencia del pensamiento de Husserl se evidencia en la obra de filósofos como Scheler, Heidegger, Hartmann, Gadamer y Ricoeur. Si bien el "mundo de la vida" repercutió en la filosofía y parecía tratarse de una exhortación a cumplir el lema de la fenomenología, "el volver a las cosas mismas", Husserl no había intentado un alejamiento de su idealismo trascendental, por el contrario, reivindicó la importancia de la intersubjetividad en la construcción del mundo porque únicamente a través de la participación común del mundo es posible imaginar la coexistencia y la relación de las mónadas entre sí (el filósofo retoma el problema de Leibniz de la coexistencia de las mónadas) pero se trata de una intersubjetividad trascendental. Recordamos que Husserl (1988) instala la subjetividad "trascendental" a partir de su crítica a Descartes, quien según él pensaba, había fallado porque a pesar de estar ante el más grande de los hallazgos: el ego cogito, no aprehendió su sentido propio, el sentido de la subjetividad trascendental, el motivo según el filósofo, fue que realizó un giro "fatal" que ontifica al ego, cuando lo convierte en substantia cogitans. Pero también cabe recordar que para Husserl (1988) el método fenomenológico no se trata de una metafisica 
ingenua ni de "cosas en sí" absurdas, en sus palabras "El ser primero en sí, el que precede a toda objetividad mundana y la soporta, es la intersubjetividad trascendental, el todo de las mónadas que se asocia en comunidad en diferentes formas" (p. 51). ${ }^{4}$ Entonces, como dice Gadamer (1998) el concepto de sujeto y el de subjetividad juegan un importante rol en la filosofia fenomenológica, hoy parece natural que signifiquen algo así como una referencia a sí mismo, entendida como reflexividad, pero la palabra griega hypokeimenon no significa nada de eso, significa, en el marco de la metafísica aristotélica, "lo que está debajo", igual que la traducción latina substantia o subjectum que remiten a lo que se mantiene invariable al cambio, a lo que subyace; si bien el sentido estaba ya predispuesto en Platón, el giro aristotélico hacia la física acercó el sujeto a la hylé como concepto para "materia" que da lugar a la metafísica de la sustancia aristotélica (p. 13).

Según Gadamer (1998) el gran cambio de orientación en el significado se produjo a través del cogito cartesiano cuya primacía epistemológica lo constituye en fundamento resistente a dudas, pero fue Kant quien entronizó el concepto de subjetividad al situar la subjetividad en la sintesis trascendental de la apercepción, que acompaña todas nuestras representaciones y les confiere unidad (p. 13). En este marco histórico conceptual se produjo el paso de la sustancia al sujeto, con ello la estructura de la reflexividad pasa a ser el núcleo central de la filosofia; "reflexividad" deriva de la expresión latina reflexio que en el campo de la óptica refería a la reflexión de la luz, filosóficamente pasó a entenderse como autoimpulso que hace visible al sí mismo. Aho-

4 Husserl profundiza la intersubjetividad trascendental en sus Meditaciones, como ejemplo alcanza con mencionar el título de la Meditación V: "En que la esfera trascendental del ser se revela como intersubjetividad monadológica" (HUSSERL, 1986, p.147). ra bien, la conciencia de sí mismo en el pensamiento moderno tiene preeminencia frente a lo dado, como correlato de la preeminencia de la certeza frente a la verdad, que fundamentó el método de la ciencia moderna (p. 15). Tanto en Descartes, como en Leibniz, como en Locke, el concepto de persona aparece definido por el concepto reflexivo de conciencia, sin que el otro aparezca en escena (Gadamer, 1998, p. 24). Luego del giro copernicano kantiano, su concepto formal de conciencia de sí mismo adquirió contenido en sus sucesores del idealismo alemán (Schelling, Hegel) pero los llamados por Ricoeur (1996) "maestros de la sospecha": Marx, Nietzsche y Freud mostraron "que no se pueden tomar ingenuamente los hechos de la conciencia por hechos de la realidad" (GADAMER, 1988, p. 16). Este aporte nos interesa principalmente en esta sección, en este marco, la interpretación se constituye en una categoría fundamental de la filosofía contemporánea.

Gadamer (1998) aclara que con Heidegger la problemática de la subjetividad se vincula con la crítica a Husserl, para Heidegger la fenomenología no es mera descripción de lo dado, también implica desvelar aquello que sirve para ocultar, así la crítica heideggeriana es radical, se centra en el concepto mismo de fenómeno, ya que la percepción de lo que se pretende percibir, queda anclada en la certeza apodíctica de la conciencia (p. 17); el filósofo descubre que en el concepto de conciencia se oculta la ontología griega, entonces resta validez tanto al concepto de conciencia como a la función básica que desempeñaba en el idealismo trascendental (p. 18). No comparte esa concepción del ser, como dice Gadamer (1998), Heidegger muestra que "La existencia no consiste en el intento siempre posterior de, adquiriendo conciencia de sí mismo, mostrarse ante uno mismo" sino que se trata de un darse a las propias representaciones y a la no-determinación del futuro; la hermenéutica de lo 
fáctico heideggeriana muestra que en la facticidad hay algo que resulta indescifrable y que resiste a todo intento de hacerlo transparente al entendimiento (p. 18); esto transforma el concepto de interpretación, si en la comprensión queda algo no desvelable, la pregunta debe dirigirse a la comprensión misma.

Según Vattimo (1991) la ontología heideggeriana es nihilista como la nietzscheana, así "ultrapasa" la metafísica porque ya no se ocupa de buscar estructuras estables, ni fundamentos eternos ni nada semejante, porque esto sería seguir pretendiendo que el ser tuviera la estructura del ente, o de la mercancía, en sentido marxiano. Para esta nueva ontología se debe captar el ser como evento, como el configurarse de la realidad ligado a la situación de la época, que por su parte proviene de épocas precedentes. El tema de esta ontología postmetafísica es escuchar los "mensajes" que provienen de otras épocas y también los mensajes de los "otros" contemporáneos; estos mensajes afectan al ser, constituyen su sentido, no se necesita ninguna estructura profunda ni ninguna ley necesaria "pero se anuncian en ellos valores históricos, configuraciones de experiencias y formas simbólicas, que son los trazos de vida, la concreciones de ser" (VATTIMO, 1991, p. 11). Esta hermenéutica conlleva una ética que busca sentidos en una ontología de la "actualidad" a modo de interpretación de eventos de lectura de los signos de los tiempos y recepción de mensajes. Según el filósofo italiano la importancia de Heidegger no consiste sólo en haber enfatizado el nexo entre ser y lenguaje, sino en haber pensado el ser como evento y no como estructura, el ser no es principio ni fundamento, sino Ge-schick: envío, transmisión, mensaje; las lenguas hacen posible la experiencia del mundo, acaecen como respuestas a otras instancias, que a su vez son respuestas a interpretaciones. Con Heidegger la hermenéutica asume radicalmen- te las implicancias de la finitud histórica del ser-lenguaje, el pensamiento en su forma de ser anuncio, no describe una estructura, sino relata un acaecimiento (VATTIMO, 1991, p. 42).

Heidegger se ocupa de la precomprensión del Dasein, la comprensión (Verstehen) es su estructura existenciaria más propia, lo que queremos destacar es que Dasein no es subjetividad, el filósofo sustituyó este concepto por el de "cuidado" (Sorge) que asoció al de solicitud, de modo que no excluyó al "otro", pero, como aclara Gadamer (1998) el problema de la intersubjetividad no es el interés del trabajo de Heidegger. Ante esa postura en la cual el otro puede mostrarse en su existencia únicamente como limitación, Gadamer dice al respecto que:

[...] al final era únicamente el refuerzo del otro en contra de uno mismo lo que ofrecía en realidad la posibilidad de comprensión. Darle al otro validez frente a uno mismo, y es a partir de aquí de donde han ido naciendo poco a poco mis trabajos hermenéuticos, no significa sólo reconocer las limitaciones de la propia perspectiva, sino que exige también ir más allá de las propias posibilidades a través de un proceso dialógico, comunicativo y hermenéutico [...] (GADAMER, 1998, pp. 22-23).

En cuanto a su posicionamiento Gadamer (1998) expresa que sus propios trabajos están orientados por el tema del lenguaje y por la primacía de la conversación, dice: "Quien piensa el lenguaje se sitúa siempre ya en un más allá de la subjetividad" (p. 25), ocurre que el filósofo toma el lenguaje como "habla" que es donde el lenguaje sucede, entonces no puede separarse lo que se dice, de aquello sobre lo cual se dice algo, de aquél a quien habla, de aquello a lo que responde (p. 34) de tal modo siempre que se habla hay un esfuerzo por entender, por conformar un lenguaje común. Entonces: “¿Qué significa en realidad comprender? Verstehen, comprender, es originariamente responder por alguien" (GADAMER, 1998, p. 
61). De allí que "La hermenéutica retiene una experiencia, no es un método para averiguar un sentido 'verdadero', como si éste pudiera llegar a alcanzarse" (p. 71). Entonces, alejado del paradigma conciencialista el sujeto que busca comprender no es dador de sentido, porque: "Allí donde se quiere que tenga lugar el comprender no puede haber nunca sólo identidad. Comprender se refiere más bien a que uno es capaz de ponerse en el lugar del otro y expresar lo que ha comprendido y qué es lo que tiene que decir sobre ello" (p. 77).

\section{c. De la vivencia a la experiencia}

La investigación narrativa en educación se ocupa de rescatar el valor de lo vivido por los protagonistas de la educación. Los relatos expresan la "trama" de la educación en su devenir, en su acontecer dinámico, cambiante y situado espacialmente por eso no es posible un posicionamiento esencialista, porque no hay una esencia (en sentido griego) que subyace como materia común que antecede y sostiene las prácticas concretas. Si se considera que la investigación narrativa es “investigación experiencial" (BOLÍVAR, DOMINGO y FERNÁNDEZ) es menester comprender de qué hablamos cuando hablamos de investigar experiencias que conforman la trama de las narrativas. Si como dice Gadamer (2003) "la forma de realización de la comprensión es la interpretación" y si "todo comprender es interpretar" (p. 467) cabe reconocer que lo que se comprende e interpreta son vivencias subjetivas pero no en sentido psicológico. Intentaremos explicitar esto a continuación.

Gadamer (2003) explica que "vivencia" es el término introducido por Ortega como traducción de Erlebnis, que era inhabitual hasta la década del 70 del siglo XIX, cuando apareció en la literatura biográfica. No aparece en el siglo anterior, su inclusión parece iniciarse en una carta de Hegel donde se refiere a un viaje.
El filósofo aclara que el término es una formación secundaria de Erleben que significa estar todavía en vida cuando sucede algo, el sentido es una comprensión inmediata de algo real, en oposición a aquello de lo que se cree saber algo pero sin la garantía que ofrece haberlo "vivido" en una "vivencia" propia, que entonces podría ser algo supuesto, imaginado, o tomado de otros. Lo vivido (das Erlebte) es siempre lo vivido por uno mismo, pero a su vez se emplea para designar el contenido permanente de lo que se ha vivido, siendo un contenido que gana significado respecto de aspectos efimeros del vivir. Lo dicho subyace a Erlebnis: la inmediatez que precede a toda interpretación, elaboración o mediación que ofrece el "soporte" o la "materia" para la configuración de la interpretación, pero a la vez, es "resultado" o "efecto" que permanece. Gadamer (2003) aclara que Dilthey emplea Erlebnis en un artículo sobre Goethe, si bien la traducción castellana de su título es "Vida y poesía", la traducción literal es "Vivencia y poesía", se trata de una edición de 1905, que ya había sido publicada en 1877 pero allí no aparece todavía con fuerza la firmeza terminológica del concepto. La acuñación de "vivencia" evoca la crítica al racionalismo de la Ilustración que a partir de Rousseau da nueva validez al concepto de vida. La apelación de Schleiermacher al sentir vivo frente al racionalismo de la Ilustración es uno de los precedentes de la protesta contra la moderna sociedad industrial, y es significativo que Dilthey fuera su biógrafo. El interés diltheyano es epistemológico: justificar el trabajo de las ciencias del espíritu, se trata de mostrar que desarrollan el mismo pathos de experiencia que las ciencias naturales (GADAMER, 2003, pp. 97-99). De la autoconciencia cartesiana y de la certeza de la regla metodológica de las percepciones claras y distintas se produce un tránsito en el siglo XIX, las creaciones del pasado no pertenecen al contenido habitual del presente, sino que 
"son objetos que se ofrecen a la investigación, datos a partir de los cuales puede actualizarse un pasado. Por eso es el concepto de lo dado el que dirige la acuñación diltheyana del concepto de vivencia" (Gadamer, 2003, p. 101).

Dice Gadamer que tanto en la filosofía de la vida como en la fenomenología, tanto en Dilthey como en Husserl, el concepto "vivencia se muestra como puramente epistemológico" ( $p$. 103). El significado es que como lo que se manifiesta en la vivencia es la vida, se trata de que es lo último a lo que podemos retroceder, pero para Gadamer hay un significado más "denso":

Cuando algo es calificado o valorado como vivencia se lo piensa como vinculado por su significación a la unidad de un todo de sentido. Lo que vale como vivencia es algo que se destaca y delimita tanto frente a otras vivencias -en las que se viven otras cosas- como frente al resto del decurso vital -en el que no se vive 'nada'-. Lo que vale como vivencia no es algo que fluya y desaparezca en la corriente de la vida de la conciencia: es algo pensado como unidad y que con ello gana una nueva manera de ser uno. En este sentido es muy comprensible que la palabra surja en el marco de la literatura biográfica (...). Aquello que puede ser denominado vivencia se constituye en el recuerdo. Nos referimos con esto al contenido de significado permanente que posee una experiencia para aquél que la ha vivido (GADAMER, 2003, p. 103).

Nos incumbe la expansión que plantea Schleiermacher en relación con la hermenéutica al aislar el procedimiento del comprender, como no acepta la restricción de la hermenéutica al terreno de las lenguas extrañas ni a los escritores, esto implica una expansión del problema hermenéutico desde la comprensión de lo fijado por escrito a la de cualquier hablar en general, este desplazamiento hace que no se trate de "comprender la literalidad de las palabras y su sentido objetivo, sino también la individualidad del hablante o del autor" (GADAMER, 2003, p. 239). En cuanto a Dilthey, la hermenéutica no es una herencia romántica, se mantiene en que toda vitalidad psíquica se encuentra bajo circunstancias, apunta al hecho de que "sólo conocemos históricamente porque nosotros mismos somos seres históricos" (GADAMER, 2003, p. 291) pero según Gadamer, Dilthey no escapa totalmente al cartesianismo, partía de la vivencia para ganar el concepto de nexo psíquico, pretendía derivar la construcción del mundo histórico a partir de la reflexividad que es inherente a la vida. Husserl intenta derivar la constitución del mundo histórico a partir de la vida de la conciencia, pero lo que nos interesa ahora es que su fenomenología trascendental pretende ser una investigación de correlaciones, donde lo primario es la relación, porque Husserl muestra la unidad de la corriente vivencial como previa y necesaria frente a la individualidad de las vivencias (GADAMER, 2003, p. 313). Notamos entonces cómo se produce un viraje desde un enfoque más psicologista hacia una mirada que si bien asume la reflexividad, prioriza lo relacional, que resignificado en el marco hermenéutico contemporáneo, no se trata de desocultar contenidos de conciencia, de allí que se hable de "experiencia" principalmente en sentido de lo experimentado en vivencias con-vividas, que en sentido gadameriano, permanecen en el recuerdo y se recuperan mediante un tipo de comprensión que involucra el diálogo o conversación en sentido antes expuesto.

Puesto que el objeto de estudio de la investigación interpretativa no se reduce a la conducta física de los sujetos sino principalmente a las interpretaciones de significado de los actores y de aquellos con quienes estos interactúan (ERICKSON, 1997), estudiar las narrativas es estudiar la forma en que los seres humanos experimentan el mundo, en el campo educativo los protagonistas son narradores y personajes de sus relatos, los mismos se caracterizan por tratarse de una construcción y reconstrucción de historias personales y so- 
ciales (CONNELLY y CLANDININ, 2000), de allí que pueda considerarse, como hemos dicho anteriormente, a la investigación narrativa como investigación experiencial.

\section{Conclusiones}

El enfoque narrativo en la investigación educativa se vincula con la hermenéutica filosófica porque interpreta vivencias lingüistizadas y porque pretende alcanzar una comprensión de las experiencias de los sujetos que son siempre intersubjetivas, no trascendentales sino concretas y situadas espacial y temporalmente. El giro hermenéutico que en cierto modo se complementa con el giro lingüístico filosófico es una salida del paradigma conciencialista; el abandono de la concepción monológica de la razón permite reconocer su carácter esencialmente dialógico.

Hemos recuperado los antecedentes más cercanos que han influido en el giro hermenéutico, mostrándolos en vinculación con tres

\section{Referencias}

APEL, Karl Otto. La transformación de la filosofia. Tomo I. Madrid: Taurus, 1985.

ARENDT, Hannah. La condición humana. Buenos Aires: Paidós, 2007.

ARFUCH, Leonor. Problemáticas de la identidad. En: ARFUCH, Leonor. (Comp.). Identidades, sujetos y subjetividades. Buenos Aires: Prometeo, 2005. p. 21-45.

BOLÍVAR, Antonio; DOMINGO, Jesús; FERNÁNDEZ, Manuel. La investigación biográfico-narrativa en educación. Enfoque y metodología. Madrid: La Muralla, 2001.

BRUNER, Jerome. Realidad mental, mundos posibles. Barcelona: Gedisa, 1988.

BRUNER, Jerome. La educación, puerta de la cultura. Madrid: Machado, 2012. ANDININ, D. Jean; CONNELLY, F. Michael. Narrative inquiry: experience and story in qualitative research. San Francisco: Jossey-Bass, 2000. conceptos centrales de la investigación narrativa en educación que abreva en la hermenéutica contemporánea. La comprensión como evento dialógico transformador que no se centra en las palabras sino en el hablante y su mundo, de tal modo la interpretación es tanto autointerpretación como interpretación del investigador, ambos siempre inmersos en un horizonte de sentido, pero también conectados mediante una interpelación interactiva; la subjetividad no a modo conciencialista sino como intersubjetividad porque se entiende como construcción entre alteridades y la experiencia cuyo sentido proviene de la vivencia pero descentrada de su sentido psicológico, más bien como experiencia de con-vivencia con otros, sino la investigación perdería de vista su sentido sociocultural y político. En nuestro recorrido a través de las transformaciones en la filosofia hermenéutica se pudo reconocer el tratamiento de la triple problemática del sentido, el lenguaje y la comprensión.

ERICKSON, Frederick. Métodos cualitativos de investigación sobre la enseñanza. En: WITTROCK, Merlin. La investigación de la enseñanza. II. Métodos cualitativos y de observación. Barcelona: Paidós, 1997. p. 203-247.

FLORES, Graciela; PORTA, Luis; MARTÍN SÁNCHEZ, Miguel. Hermenéutica y narratividad en el discurso cualitativo de la Educación. Revista Entramados, Educación y Sociedad, Facultad de Humanidades de la UNMdP, Argentina, año 1, n. 1, p. 69-81, 2014.

GADAMER, Hans George. El giro hermenéutico. Cátedra: Madrid, 1998.

GADAMER, Hans George. Verdad y método. v. I. Salamanca: Sígueme, 2003.

HEIDEGGER, Martin. Ser y tiempo. Santiago de Chile: Universitaria, 1998.

HUSSERL, Edmund. Las conferencias de París. Intro- 
ducción a la Fenomenología Trascendental. México: UNAM, 1988.

HUSSERL, Edmund. Meditaciones cartesianas. México: Fondo de Cultura Económica, 1986.

MACINTYRE, Alasdair. Tras la virtud. Barcelona: Crítica, 2008.

MALIANDI, Ricardo. Transformación y síntesis. Buenos Aires: Almagesto, 1991.

MALIANDI, Ricardo. Ética: conceptos y problemas. Buenos Aires: Biblos, 2004.

MÉLICH, Joan Carles. Transformaciones. Tres ensayos de filosofía de la educación. Buenos Aires: Miño y Dávila, 2006.

PORTA, Luis; SARASA, María Cristina; ÁLVAREZ, Zelmira. Una experiencia en torno a la investigación sobre la enseñanza en el nivel superior. Revista de Educación de la Universidad Nacional de Mar del Plata, año 2, n. 3, p. 181-210, 2011.

RICOEUR, Paul. Hermenéutica y estructuralismo. Buenos Aires: La Aurora, 1975a.
RICOEUR, Paul. Hermenéutica y psicoanálisis. Buenos Aires: La Aurora, 1975b.

RICOEUR, Paul. Sí mismo como otro. Madrid: Siglo XXI, 1996.

RICOEUR, Paul. Epílogo. Narratividad, fenomenología y hermenéutica. En: ARANZUEQUE, Gabriel. Horizontes del relato. Lecturas y conversaciones con Paul Ricoeur. Madrid: Cuaderno Gris, 1997. p. 479495.

SARASA, María Cristina. Reflexiones en torno a la creación del espacio biográfico. Entrevista a Leonor Arfuch. Revista de Educación de la Universidad Nacional de Mar del Plata, año 3, n. 4, p. 185-192, 2012.

TAYLOR, Charles. Fuentes del yo. La construcción de la identidad moderna. Barcelona: Paidós, 1996.

VATTIMO, Gianni. Ética de la interpretación. Barcelona: Paidós, 1991.

Luis Gabriel Porta Universidad Nacional de Mar del Plata. Profesor Titular de la asignatura Problemática Educativa. Departamento de Ciencias de la Educación. Director del Grupo de Investigaciones em Educación y Estudios Culturales. Centro de Investigaciones Multidisciplinarias en Educación (CIMED). Investigador Independiente de CONICET. e-mail: luisporta510@gmail.com

Funes 3375 - Teléfono: 542234752277

Graciela Nelida Flores Universidad Nacional de Mar del Plata. Docente em la cátedra Problemática Educativa. Departamento de Ciencias de la Educación. Forma parte del Grupo de Investigaciones em Educación y Estudios Culturales (GIEEC). Centro de Investigaciones Multidisciplinarias en Educación (CIMED).

e-mail: gracielaflores9-1@hotmail.com

Funes 3375 - Teléfono: 542234752277 